\title{
On the association of common and rare genetic variation influencing body mass index: a combined SNP and CNV analysis
}

\author{
Roseann E Peterson ${ }^{1 *}$, Hermine H Maes ${ }^{2}$, Peng Lin ${ }^{3}$, John R Kramer ${ }^{4}$, Victor M Hesselbrock ${ }^{5}$, Lance O Bauer ${ }^{5}$,
} John I Nurnberger $\mathrm{Jr}^{6}$, Howard J Edenberg ${ }^{7}$, Danielle M Dick ${ }^{8}$ and Bradley T Webb ${ }^{9}$

\begin{abstract}
Background: As the architecture of complex traits incorporates a widening spectrum of genetic variation, analyses integrating common and rare variation are needed. Body mass index (BMI) represents a model trait, since common variation shows robust association but accounts for a fraction of the heritability. A combined analysis of single nucleotide polymorphisms (SNP) and copy number variation (CNV) was performed using 1850 European and 498 African-Americans from the Study of Addiction: Genetics and Environment. Genetic risk sum scores (GRSS) were constructed using $32 \mathrm{BMI}$-validated SNPs and aggregate-risk methods were compared: count versus weighted and proxy versus imputation.

Results: The weighted SNP-GRSS constructed from imputed probabilities of risk alleles performed best and was highly associated with BMI $\left(p=4.3 \times 10^{-16}\right)$ accounting for $3 \%$ of the phenotypic variance. In addition to BMI-validated SNPs, common and rare BMI/obesity-associated CNVs were identified from the literature. Of the 84 CNVs previously reported, only 21-kilobase deletions on 16p12.3 showed evidence for association with BMI $(p=0.003$, frequency $=16.9 \%)$, with two CNVs nominally associated with class II obesity, 1 p36.1 duplications $(\mathrm{OR}=3.1, \mathrm{p}=0.009$, frequency $1.2 \%)$ and $5 q 13.2$ deletions ( $O R=1.5, p=0.048$, frequency $7.7 \%)$. All other CNVs, individually and in aggregate, were not associated with BMI or obesity. The combined model, including covariates, SNP-GRSS, and 16p12.3 deletion accounted for 11.5\% of phenotypic variance in BMI (3.2\% from genetic effects). Models significantly predicted obesity classification with maximum discriminative ability for morbid-obesity $\left(p=3.15 \times 10^{-18}\right)$.
\end{abstract}

Conclusion: Results show that incorporating validated effect sizes and allelic probabilities improve prediction algorithms. Although rare-CNVs did not account for significant phenotypic variation, results provide a framework for integrated analyses.

Keywords: Body mass index, Obesity, Genome-wide association, Copy number variation, Risk prediction, Polygenic score, FTO, MC4R

\section{Background}

Obesity, defined clinically by a body mass index (BMI) $\geq$ $30 \mathrm{~kg} / \mathrm{m}^{2}$, is a serious public health problem that occurs in over 1/3 of American adults [1,2] and is associated with numerous medical conditions including cardiovascular disease [3], type II diabetes [4], and cancer [5]. Although nutritional intake and physical activity are known to affect relative

\footnotetext{
* Correspondence: repeterson@vcu.edu

'Virginia Institute for Psychiatric and Behavioral Genetics, Department of Human and Molecular Genetics, School of Medicine, Virginia Commonwealth University, Biotech I, 800 E. Leigh Street, Richmond, VA 23298-0126, USA Full list of author information is available at the end of the article
}

body weight, twin and family studies have consistently shown a significant genetic contribution to body composition with heritability estimates of 40 to $70 \%$ [6].

Genome-wide association studies (GWAS) have successfully identified single nucleotide polymorphisms (SNPs) that contribute to individual variation in BMI and common obesity $[7,8]$. In general adult populations of European descent, there are 32 SNPs showing robustly replicated association with BMI. However, individual variants have relatively small effects (0.06 to $0.39 \mathrm{~kg} / \mathrm{m}^{2}$ in BMI per risk allele among Europeans) and in aggregate account for only a

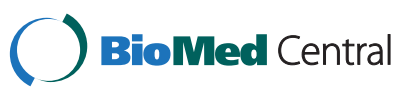


limited proportion of the phenotypic variance $(\sim 1.45 \%)$ [9]. GWAS of BMI in populations of African ancestry are limited but initial reports suggest a portion of the European-associated variants may also be associated across diverse populations [10-14].

Whereas reported single marker associations account for only a limited fraction of trait variance, linear mixed model approaches simultaneously consider the effects of common variation across the entire genome. As applied to BMI, this approach has demonstrated that common SNPs account for up to $17 \%$ of the phenotypic variance in BMI [15]. However, given that reported heritability estimates for BMI are typically much higher (40-70\% [6]), a substantial proportion of the variance remains unaccounted for. To what extent this "missing heritability" is attributable to rare or structural variation is increasingly of interest to researchers and supported by a growing list of rare copy number variants $(\mathrm{CNV})$ reported to be associated with BMI and obesity [16-24].

Given the widening spectrum of genetic variation demonstrated to be associated with common, complex traits, there is a need for genetic models integrating common and rare variants. In this study, we constructed a model that jointly incorporated the effects of common and rare $(<1 \%)$ variants shown previously to be associated with obesity. First, genetic variants associated with BMI and obesity were catalogued from the literature, including common SNPs and common and rare CNVs. Next, genetic risk sum scores (GRSS), which summarize the total number of risk variants, were tested for association with BMI in 1850 Americans of European (EA) and 498 African (AA) descent from the Study of Addiction: Genetics and Environment (SAGE). Finally, we evaluated clinical utility of these models on the basis of discriminative ability to predict obesity classification.

\section{Methods}

\section{Participants and phenotypes}

Participants were from the Study of Addiction: Genes and Environment (SAGE) [25]. All SAGE participants provided written informed consent for genetic studies and agreed to share their DNA and phenotypic information for research purposes. All samples were de-identified and only subjects who consented to health research were included. The institutional review boards at all data collection sites granted approval for use of the data (Washington University in St. Louis, Henry Ford Health Sciences Center, Indiana University, The State University of New York Downstate Medical Center, University of Connecticut Health Center, University of California San Diego).

Study variables were assessed by interview, using versions of the Semi-Structured Assessment for the Genetics of Alcoholism (SSAGA) [26]. BMI was calculated from self- reported height and weight. Participants were removed from data analysis if they had missing data on either height or weight, height was $<1.4$ or $>2$ meters, weighed $<38$ or $>$ $166 \mathrm{~kg}$, or if calculated BMI was $<14.5$ or $>60 \mathrm{~kg} / \mathrm{m}^{2}$, as values not in these ranges were likely due to data entry errors or suggestive of eating or syndromic disorders $(n=12)$. Clinical bodyweight categories were defined as overweight $\left(B M I \geq 25 \mathrm{~kg} / \mathrm{m}^{2}\right)$, obese class I $\left(B M I \geq 30 \mathrm{~kg} / \mathrm{m}^{2}\right)$, II $\left(B M I \geq 35 \mathrm{~kg} / \mathrm{m}^{2}\right)$ and III $\left(B M I \geq 40 \mathrm{~kg} / \mathrm{m}^{2}\right)$. Age was included as age at interview in years. Alcohol dependence (AD) was defined by the SSAGA according to DSM-IV criteria [27] and nicotine dependence (ND) was defined as having a Fagerström Test for Nicotine Dependence score of 4 or greater as assessed from the SSAGA.

Complete data on height, weight, AD, ND, genotypes and CNVs were available for $1850 \mathrm{EA}$ and 498 AA participants. Descriptive statistics for study variables are presented by sex and self-reported ancestry in Table 1 . There was a significant race by sex interaction with BMI $\left(t\right.$-test $\left.=6.84, \mathrm{p}=1.01 \times 10^{-11}\right)$ indicating that females and AAs tended to have greater BMI. Males were more likely to be $\mathrm{AD}\left(\chi^{2}=286.02, \mathrm{p}=3.65 \times 10^{-64}\right)$ and $\mathrm{ND}\left(\chi^{2}=\right.$ 9.36, $\mathrm{p}=0.002)$. The age by AD interaction was also significant ( $t$-test $=-3.11, \mathrm{p}=0.002)$ indicating that older subjects were less likely to be AD.

\section{Genotyping}

Samples were genotyped on the Illumina Human $1 \mathrm{M}$ beadchip at the Center for Inherited Diseases Research at Johns Hopkins University. Details of quality control procedures have been previously reported [25]. Analysis was restricted to SNPs with minor allele frequency $\geq 1 \%$, call rate $\geq 98 \%$ and Hardy-Weinberg Equilibrium p-value $\geq$ $10^{-5}$. IMPUTE2 was used to phase the observed genotypes and impute unobserved genotypes $[28,29]$ using the 1000 Genomes phase 1 reference panel (release June 2011, b37) [30] separately by ancestry. To minimize effects of population stratification, 577,039 SNPs were used to generate ten principal components (PC) using EIGENSOFT 3.0 [31] and SMARTPCA [32]. To circumvent over-fitting only PCs that were associated with BMI and indicative of ancestral background were used in subsequent analyses [31-33]. The software Quanto was used to assess the power of the SAGE sample $(n=2,348)$ to detect known BMI/obesity genetic variants [34]. These calculations were computed using descriptive statistics reported in original papers, which included variant frequency, effect size, odds-ratio and percent variance accounted for.

\section{CNV calling}

The Illumina $1 \mathrm{M}$ array has 1,072,820 probes (which includes 23,812 non-SNP "intensity-only" markers) that were used for $\mathrm{CNV}$ detection. Three widely-used programs were used for CNV calling: CNVPartition (Illumina StudioBead 
Table 1 Descriptive statistics by sex and self-reported ancestry

\begin{tabular}{|c|c|c|c|c|}
\hline \multirow[t]{2}{*}{ Variable } & \multicolumn{2}{|c|}{ Men } & \multicolumn{2}{|c|}{ Women } \\
\hline & $\begin{array}{c}\text { Mean EA } \\
\text { (SD) } n=780\end{array}$ & $\begin{array}{c}\text { Mean } A A \\
\text { (SD) } n=231\end{array}$ & $\begin{array}{c}\text { Mean EA (SD) } \\
n=1070\end{array}$ & $\begin{array}{c}\text { Mean AA } \\
\text { (SD) } n=267\end{array}$ \\
\hline Age & $40.4(9.7)$ & $41.1(8.3)$ & $39.3(9.0)$ & $39.3(6.9)$ \\
\hline \multirow[t]{2}{*}{$B M I$} & $27.5(4.6)$ & $28.4(5.1)$ & $26.5(6.5)$ & $31.5(7.3)$ \\
\hline & $n(\%)$ & $n(\%)$ & $n(\%)$ & $n(\%)$ \\
\hline Obese & $184(23.6 \%)$ & $72(31.2 \%)$ & $246(23.0 \%)$ & $130(48.7 \%)$ \\
\hline$A D$ & $501(64.2 \%)$ & 171 (74.0\%) & $300(28.0 \%)$ & $120(44.9 \%)$ \\
\hline ND & 406 (52.1\%) & 125 (54.1\%) & $466(43.6 \%)$ & $151(56.6 \%)$ \\
\hline
\end{tabular}

Note: $\mathrm{EA}=$ European-American, $\mathrm{AA}=$ African-American, $\mathrm{SD}=$ standard deviation, Age = age at interview in years, $B M I=$ body mass index $\mathrm{kg} / \mathrm{m}^{2}$, Obese $=\mathrm{BMI} \geq 30 \mathrm{~kg} / \mathrm{m}^{2}, \mathrm{AD}=$ alcohol dependence, $\mathrm{ND}=$ nicotine dependence.

software), PennCNV [35], and QuantiSNP [36]. Genomic waves were adjusted for CNVs called by PennCNV and QuantiSNP [37]. Both PennCNV and QuantiSNP report a metric score for quality control purposes and CNV calls with a Log Bayes Factor less than ten were removed as well as poor quality samples based on quality control measures for $\mathrm{CNV}$ analysis as described in our previous work [38]. $\mathrm{CNV}$ calls from the three programs were compared and integrated using Combined CNV (CNVision.org) [39]. To increase the positive predicative rate [38], only CNVs that were called by at least two programs, as defined by $\geq$ $50 \%$ reciprocal overlap, were analyzed. Given that calls in centromeric, telomeric and immunoglobin regions are prone to harbor false positives, CNV calls in those regions were removed from analyses (33 regions, 13941 calls) $[35,40]$.

\section{Selection of BMI/obesity-associated genetic variation}

BMI SNPs were catalogued from a BMI meta-analyses by Speliotes and colleagues [9]. The meta-analyses identified 32 SNPs reaching genome-wide significance $(\mathrm{p}<$ $5 \times 10^{-8}$ ) (Additional file 1: Table S1). The SAGE sample was not included in the meta-analysis and represents and independent sample to test BMI loci. Fifteen SNPs did not appear on the genotyping array. Ungenotyped markers were ascertained by two approaches in order to compare methods: 1) imputation and 2) proxy SNPs. Imputed SNPs analyzed had allele frequency greater than 1\% (Additional file 1: Table S1) and imputation quality greater than 0.8 . The proxy method used the LD structure of the genome to identify highly correlated SNPs that appear on the array as substitutes for the unobserved SNPs. Proxy SNPs were identified using SNP Annotation and Proxy Search V2.1 [41] using the HapMap release 22 CEU reference panel except for rs11847697, which did not have a highly correlated SNP $\left(\mathrm{r}^{2}<0.7\right)$ and was therefore not included in SNP-GRSSs. Proxy SNP information appears in Additional file 1: Table S1b. BMI and obesity associated CNVs were catalogued from research published between January 2008 and January 2012 via PubMed search (Additional file 2: Table S2). Case reports, typical of monogenic inheritance, were not included in the catalogue as the focus of the current study was on common complex obesity.

\section{BMI SNP genetic risk sum scores}

Primarily two methods exist for constructing genetic scores: count and weighted methods. The count method is the sum of the number of risk alleles, whereas the weighted method incorporates the sum of the number of risk alleles each weighted by its odds-ratio or effect size. In this study, the weighted scores were constructed from regression coefficients reported by Speliotes et al. [9]. Count and weighted scores using the proxy method were calculated using the profile option in PLINK [42]. If SNP information was missing in an individual then the scoring routine imputed expected values based on sample allele frequency. Count and weighted scores using imputed genotypes were constructed using $\mathrm{R}$ version 2.13.1(script available upon request to R.E.P.) [43]. Furthermore, to extend existing GRSS methodology [44], count and weighted scores were constructed using probabilities of imputed risk alleles $(p)$ by the equation below (Equation 1 ). Count scores were calculated with $\beta=1$ and weighted scores with $\beta=$ effect size of each risk allele (A) reported by Speliotes et al. [9] summed over the number of risk alleles in the score (n). To determine if there was significant effect size differences by GRSS methodology z-scores were computed in R using Equation 2 and p-values assigned based on the standard normal distribution.

$$
\begin{aligned}
& \left(\sum_{1}^{n} \beta[(2 * p(A A))+p(A a)]\right) / n \\
& Z=\frac{\left(e s_{1}-e s_{2}\right)}{\sqrt[2]{\left(s e_{1}^{2}+s e_{2}^{2}\right)}}
\end{aligned}
$$

\section{CNV association}

In the SAGE sample, CNVs with a frequency $\geq 1 \%$ were considered common, those with a frequency $<1 \%$ rare. Common BMI/obesity-associated CNVs were tested individually as well as in aggregate by count scores. The limited number of rare CNV variants expected to be detected in the SAGE sample made statistical analysis of individual rare $\mathrm{CNVs}$ inappropriate $[45,46]$. Therefore, rare $\mathrm{BMI} /$ obesity-associated CNVs were tested by aggregate count scores (CNV-GRSSs). Additionally, since rare CNV burden scores have been associated with obesity $[16,19]$, the genome-wide load of rare CNVs was also tested by the count method. CNVs previously reported to be associated with $\mathrm{BMI} /$ obesity were considered the same region in the SAGE sample if the CNV boundaries 
shared at least $40 \%$ overlap with the CNV boundaries reported in the literature. Furthermore, since there is evidence that the positive predictive rate is increased for large CNVs, which is likely due to the increased number of probes in larger variants, common and rare scores were also constructed from $\mathrm{CNVs} \geq 100-\mathrm{kb}$ to potentially reduce the number of false positive calls in the score [38].

\section{Linear models}

$\mathrm{R}$ [43] was used to fit linear and logistic regression models using established covariates for BMI including PCs associated with BMI and ancestry, sex and age. AD and ND were also included as covariates since the SAGE sample was selected for these traits. Predictors in linear models were included in a stepwise process and independent variables were centered to facilitate interpretation of effects. Interactions between covariates and predictors were tested and included in the final model if the p-value of the interaction was less than the Bonferroni corrected significance level of 0.002 .

\section{Prediction of obesity}

To test whether the combined model of common and rare variation had clinical utility for obesity risk prediction, we assessed diagnostic efficiency by calculating the area under the (AUC) receiver operator criteria (ROC) curves, which is a plot of the true positive rate (sensitivity) against the false positive rate (1 - specificity). Binary logistic regression was used to calculate predicted probabilities of the models. SPSS Statistics version 19.0 was used for AUC analyses and the StAR software was used to test for statistical differences between ROC curves [47].

\section{Results \\ BMI SNP-GRSS}

Seven of the 32 BMI-SNPs were found to be associated with BMI in the SAGE sample $(\mathrm{p}<0.01)$, which included SNPs in or near FTO and BDNF (Additional file 1: Table S1). The mean number of BMI risk alleles per person was $28.5(\mathrm{SD}=3.4)$ with a range from 18 to 39 and the distribution is presented by self-reported ancestry in Figure 1. As shown in Table 2, the SNP-GRSS was highly significantly associated with $\mathrm{BMI}$ in the combined sample $\left(\mathrm{p}<1.11 \times 10^{-12}\right)$ and accounted for $3.1 \%$ of the variance. Examining GRSSs by ancestry indicated that point estimates for effect size and percent of variance accounted for in BMI tended to be greater in EA than AA sample (Additional file 3: Table S3a). However, there were no statistical differences in GRSS effect sizes $(\mathrm{p}>0.138)$ when comparing by ancestry (Additional file 3: Table S3b). Although there were no statistical differences in effect sizes by GRSS method, the proportion of variance in
BMI accounted for increased by $0.6-0.9 \%$ when using weighted scores and in the EA sample an additional $0.2 \%$ when incorporating imputed genotype probabilities (Additional file 3: Table S3c).

\section{CNV association}

Eighty-four BMI/obesity-associated CNVs were catalogued from the literature and tested for association with BMI and obesity in the SAGE sample (Additional file 2: Table S2). Of the common CNVs, only a $21-\mathrm{kb}$ deletion on 16p12.3 showed evidence for association with BMI $(\beta=-0.057, p=0.003$, frequency $=16.9 \%)$. This $\mathrm{CNV}$ was also nominally associated with obese class $\mathrm{I}(\mathrm{OR}=0.743$, $\mathrm{p}=0.022)$ and II $(\mathrm{OR}=0.630, \mathrm{p}=0.020)$. We would like to note that this CNV is correlated with SNP rs12444979, which was included in the GRSS $(r=0.798)$. However, since they were not in perfect LD and diagnostics between them did not suggest multicolinearity (variance inflation factor $<2.8$ ) we chose to include both in subsequent analyses because it is possible that the SNP is capturing variation beyond the effect of the CNV. Additionally, rs2815752 near NEGR1 has been previously shown to tag a common deletion $[9,48,49]$. Although the SNP (included in the SNP-GRSS) was nominally associated ( $p=0.007$ ) with BMI the CNV was not, which could be due in part to the low call rate of this deletion in SAGE $(<1 \%)$. There were two additional common CNVs nominally associated with class II obesity. The first was a duplication on $1 \mathrm{p} 36.1(\mathrm{OR}=3.1, \mathrm{p}=0.009$, frequency $1.2 \%)$ which ranged in length from 49.3 to $150.8 \mathrm{~kb}$ with a median value of $66.4 \mathrm{~kb}$. The second was a large deletion on $5 \mathrm{q} 13.2(\mathrm{OR}=$ $1.5, p=0.048$, frequency $7.7 \%$ ) and ranged in length from 577.5 to $2238 \mathrm{~kb}$ with a median value of $1635 \mathrm{~kb}$. None of the CNV-GRSSs, common or rare, were significantly associated with BMI or obesity in the SAGE sample. Descriptive statistics as well as association results for CNV-GRSSs are presented in Additional file 4: Table S4.

\section{Models incorporating effects of SNPs and CNVs}

Results from linear regression analyses are displayed in Table 3. Model 1, which included the standard covariates, PC1 by sex and age by AD interactions but no genetic component, accounted for $8.3 \%$ of the variance in BMI. Model 2, which added the SNP-GRSS and the 21$\mathrm{kb}$ deletion on 16p12.3 to the base model, fit significantly better $\left[\mathrm{F}_{(3233)}=25.3, \mathrm{p}=3.34 \mathrm{x}^{-54}\right]$ and accounted for an additional $3.2 \%$ of phenotypic variance $(3.1 \%$ due to SNP-GRSS, $0.1 \%$ due to deletion on 16p12.3) in BMI for a total of $11.5 \%$. Interactions between the covariates and the SNP-GRSS were not significant except for sex, which suggested that the SNP-GRSS was statistically similar in EA and AA and across age but tended to account for more of the variation in females. No significant interactions between the covariates and the $21-\mathrm{kb}$ 


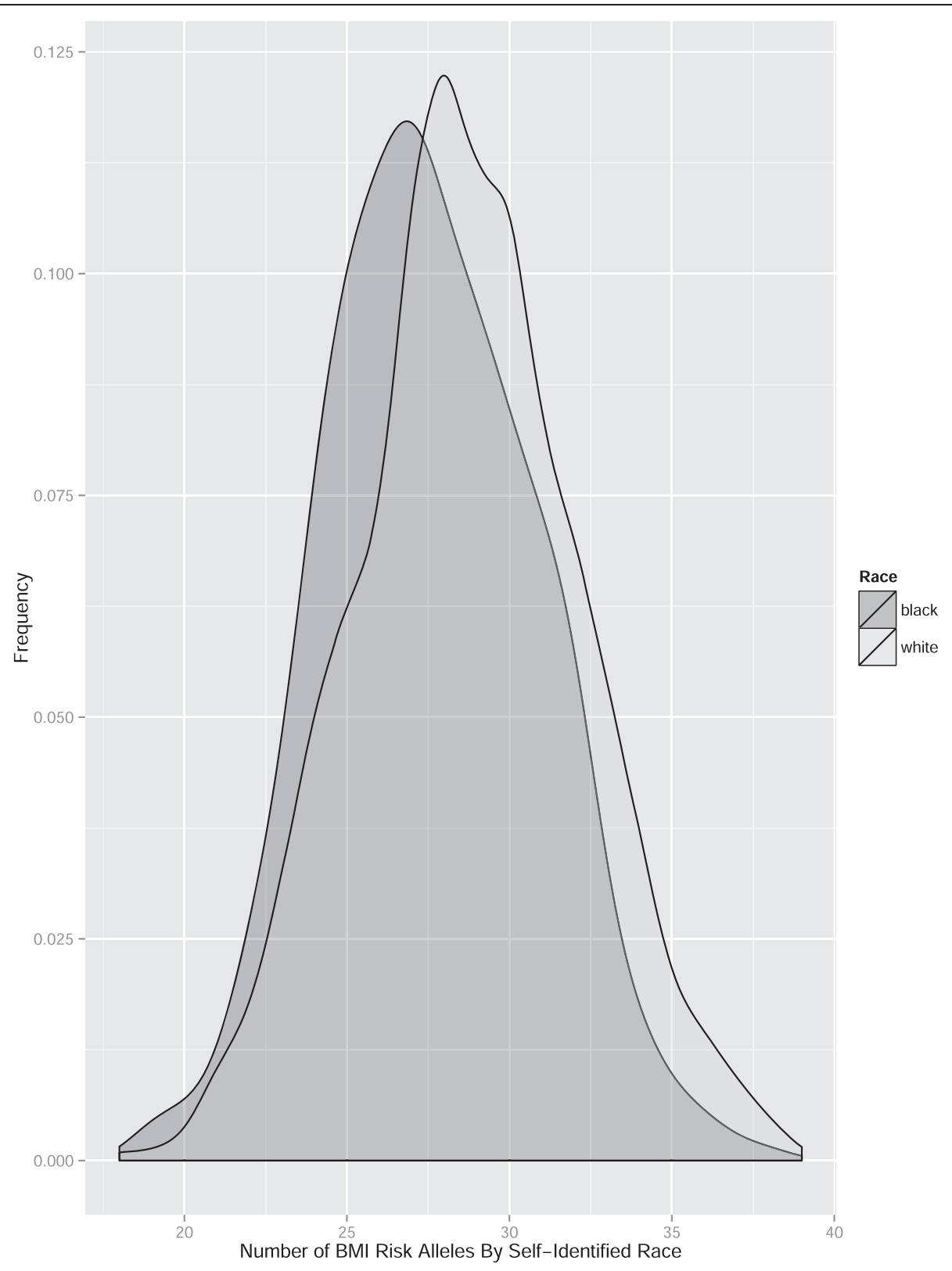

Figure 1 Distribution of BMI-risk alleles by ancestry. Note: $\mathrm{BMI}=$ body mass index $\mathrm{kg} / \mathrm{m}^{2}$.

Table 2 Comparison of the association of GRSSs with BMI constructed by count and weighted methods

\begin{tabular}{|c|c|c|c|c|c|}
\hline GRSS Method & Mean (SD) & $E S$ (SE) & $T$ & p-value & $R^{2}$ \\
\hline 1. Proxy count & $0.450(0.06)$ & $0.927(0.129)$ & 7.18 & $9.07 \times 10^{-13}$ & 0.022 \\
\hline 2. Proxy weighted & $0.063(0.01)$ & $1.104(0.129)$ & 8.56 & $2.05 \times 10^{-17}$ & 0.027 \\
\hline 3. Imputed count & $0.447(0.05)$ & $0.865(0.121)$ & 7.16 & $1.11 \times 10^{-12}$ & 0.022 \\
\hline 4. Imputed weighted & $0.062(0.01)$ & $1.035(0.122)$ & 8.51 & $2.94 \times 10^{-17}$ & 0.030 \\
\hline 5. Imputed probability count & $0.894(0.11)$ & $0.872(0.121)$ & 7.21 & $7.33 \times 10^{-13}$ & 0.022 \\
\hline 6. Imputed probability weighted & $0.124(0.02)$ & $1.037(0.122)$ & 8.54 & $2.43 \times 10^{-17}$ & 0.031 \\
\hline
\end{tabular}

Note: $\mathrm{BMI}=$ body mass index $\mathrm{kg} / \mathrm{m}^{2}$, GRSS = genetic risk sum score, Mean = mean GRSS, ES = effect size for GRSS, Count = GRSS constructed from the summation of the number of risk alleles, Weighted = GRSS constructed from the number of risk alleles weighted by effect-sizes reported in Speliotes et al. 2010, SNP $=$ single nucleotide polymorphism, Proxy = highly correlated substitute SNPs were used for variants not directly genotyped, Imputed = genotypes inferred from 1000 Genomes reference panel, Imputed probability = probability of genotypes inferred from 1000 Genomes reference panel. 
deletion on 16p12.3 were found, which indicated that the $\mathrm{CNV}$ was comparably associated with $\mathrm{BMI}$ in males and females, EA and AA and across the age range observed in SAGE. Additional file 5: Table S5 gives full model statistics by ancestry. We have also included in Additional file 5: Table S5d models with the two SNPs (rs12444979, rs2815752) that have been previously shown to tag CNVs removed from the SNP-GRSS and did not find any major differences in model fit (i.e.; $\left[F_{(12} 2,335\right)=$ 25.34 , $\mathrm{p}$-value $\left.=3.34 \times 10^{-54}, \mathrm{R}^{2}=0.115\right]$ vs. $\left[\mathrm{F}_{(12} 2,335\right)=$ 24.54, $\mathrm{p}$-value $\left.=1.97 \times 10^{-52}, \mathrm{R}^{2}=0.112\right]$ ).

\section{Obesity risk prediction}

To test the discriminative accuracy of models to predict obesity classification, ROC curves were plotted and the corresponding AUCs were calculated. Three sets of nested models were tested: 1) covariates (PCs, sex, age, ancestry by sex interaction), 2) covariates, SNP-GRSS and interaction with sex and 3) covariates, SNP-GRSS and three obesity-associated CNVs (the $21 \mathrm{~kb}$ deletion on 16p.12.3, the $66 \mathrm{~kb}$ duplication on 1p36.1, and the $1440 \mathrm{~kb}$ deletion on 5q13.2). Table 4 displays fit statistics from ROC curve analysis by BMI category (Additional file 6: Table S6 displays by ancestry). AUC estimates indicated the models significantly predicted overweight and obesity classification with maximum discriminative ability when employing model 3 to predict class III obesity $(\mathrm{AUC}=0.750,95 \% \mathrm{CI}=[0.702,0.797])$. Models that included genetic information had significantly greater AUCs than models only including covariates (Table 4).

\section{Discussion and conclusions}

We have constructed an integrated model of common and rare variation catalogued from the literature and demonstrated its association with BMI in 1850 European-American and 498 African-American SAGE participants. This study is among the first to incorporate both SNPs and CNVs in a joint genetic analysis of BMI

Table 3 Linear models predicting BMI

\begin{tabular}{|c|c|c|c|c|c|c|}
\hline Model & Estimate EA & Estimate AA & Estimate combined & $p$-value EA & $p$-value AA & $p$-value combined \\
\hline \multicolumn{7}{|c|}{ Model 1: Covariates } \\
\hline Intercept & 26.91 & 30.21 & 27.63 & $<2 \times 10^{-16}$ & $<2 \times 10^{-16}$ & $<2 \times 10^{-16}$ \\
\hline PC1 & -50.11 & -6.91 & -98.82 & 0.788 & 0.939 & $2.40 \times 10^{-29}$ \\
\hline PC4 & 19.31 & -29.93 & 10.54 & 0.027 & 0.157 & 0.167 \\
\hline PC8 & -3.18 & -28.41 & -30.20 & 0.934 & 0.008 & 0.002 \\
\hline Sex & -1.26 & 2.49 & -0.46 & $1.76 \times 10^{-5}$ & $3.67 \times 10^{-5}$ & 0.081 \\
\hline Age & 0.05 & -0.01 & 0.04 & $2.13 \times 10^{-4}$ & 0.984 & $9.45 \times 10^{-4}$ \\
\hline$A D$ & -0.15 & -0.37 & -0.20 & 0.062 & 0.018 & 0.004 \\
\hline ND & -0.10 & 0.07 & -0.06 & 0.157 & 0.627 & 0.361 \\
\hline$P C 1 *$ Sex & 295.12 & -249.00 & -122.29 & 0.409 & 0.172 & $1.92 \times 10^{-12}$ \\
\hline Age $^{*} A D$ & -0.02 & -0.07 & -0.02 & 0.026 & 0.0006 & $3.20 \times 10^{-4}$ \\
\hline \multicolumn{7}{|c|}{ Model 2: Covariates, GRSS \& CNV } \\
\hline Intercept & 26.91 & 30.22 & 27.63 & $<2 \times 10^{-16}$ & $<2 \times 10^{-16}$ & $<2 \times 10^{-16}$ \\
\hline PC1 & -107.10 & -14.09 & -110.22 & 0.560 & 0.877 & $1.89 \times 10^{-35}$ \\
\hline PC4 & 20.20 & -30.04 & 10.14 & 0.019 & 0.153 & 0.176 \\
\hline PC8 & 11.44 & -30.56 & -31.53 & 0.765 & 0.004 & $8.36 \times 10^{-4}$ \\
\hline Sex & -1.24 & 2.51 & -0.43 & $1.70 \times 10^{-5}$ & $2.89 \times 10^{-5}$ & 0.099 \\
\hline Age & 0.05 & 0.01 & 0.04 & $2.03 \times 10^{-4}$ & 0.963 & $8.15 \times 10^{-4}$ \\
\hline$A D$ & -0.15 & -0.37 & -0.20 & 0.058 & 0.020 & 0.005 \\
\hline ND & -0.12 & 0.09 & -0.07 & 0.087 & 0.566 & 0.253 \\
\hline$P C 1 *$ Sex & 170.80 & -261.80 & -131.38 & 0.627 & 0.150 & $3.91 \times 10^{-14}$ \\
\hline Age $^{*} A D$ & -0.01 & -0.06 & -0.02 & 0.032 & 0.001 & $6.59 \times 10^{-4}$ \\
\hline SNP-GRSS & 65.40 & 42.30 & 62.44 & $2.55 \times 10^{-15}$ & 0.036 & $4.30 \times 10^{-16}$ \\
\hline Sex*SNP-GRSS & 39.96 & 70.47 & 44.37 & 0.014 & 0.076 & 0.003 \\
\hline Del 16p12.3 & -0.60 & -0.61 & -0.57 & 0.079 & 0.511 & 0.075 \\
\hline
\end{tabular}

Note: $\mathrm{BMI}=$ body mass index $\mathrm{kg} / \mathrm{m}^{2}$, Estimate $=$ regression coefficient, $\mathrm{EA}=$ European-American, $\mathrm{AA}=\mathrm{African}-$ American, $\mathrm{GRSS}=\mathrm{genetic}$ risk sum score, $\mathrm{PC}=$ principal component score, $\mathrm{Age}=$ age at interview in years, $\mathrm{AD}=$ alcohol dependence, $\mathrm{ND}=$ nicotine dependence, $\mathrm{CNV}=$ copy number variation, $\mathrm{Del}=\mathrm{deletion}$.

* $=$ interaction term. 
and obesity risk prediction. Our best- fitting model included standard covariates, SNP-GRSS and a 21-kb deletion on $16 \mathrm{p} 12.3$, and accounted for $11.5 \%$ of the phenotypic variance in BMI $\left(\mathrm{p}=3.34 \times 10^{-54}\right)$.

The effects of 32 BMI-associated SNPs were incorporated via an aggregate risk score and accounted for up to $3.1 \%$ of the variance in BMI. Comparison of SNP-GRSS methodology indicated that a weighted score resulted in a $0.6-0.9 \%$ increase in the amount of variance accounted for. Furthermore, in the EA sample incorporating the probability of risk alleles from imputation further increased the amount of variance accounted for in BMI. The effect of the score tended to be lower in the AA sample. Due to the limited sample size of the AA group it could not be determined with confidence if indeed the effect of the score on BMI differed by ancestry. However, a study by Belsky et al. report that a genetic score of BMI-associated SNPs tended to be less significant in an AA sample compared to those from the EA sample [50]. These findings highlight the value of large-scale metaanalysis validation efforts to characterize effect sizes for genetic variants. Future research should test these methods for improved risk prediction in other complex traits and diseases and in diverse populations.

Of $84 \mathrm{BMI} /$ obesity-associated CNVs catalogued from the literature, only 46 were detected in SAGE and only one, $16 \mathrm{p} 12.3$ deletion, was significantly associated with
BMI. Speliotes et al. first reported the 16p12.3 deletion in a large-scale meta-analysis because a common BMIdecreasing allele was highly correlated with the same $21 \mathrm{~kb}$ deletion [9]. In the present study, the CNV was also moderately associated with obesity classes I and II. Additionally, two common CNVs on 1p36.1 and 5q13.2 were nominally associated with class II obesity. Our results did not yield additional support for the other BMI/obesityassociated CNVs, which might reflect limited power in the SAGE sample to detect the range of effect sizes, even when aggregate effects were considered. However, only 4 of the 84 CNVs identified from the literature have been associated with BMI/obesity in multiple studies. To that point, a recent study by Walters et al. attempted to replicate $18 \mathrm{BMI} /$ obesity-associated CNVs and only replicated a rare $220 \mathrm{~kb}$ deletion on 16p11.2 [51]. Therefore, it is conceivable that the collections of CNVs examined here contained a greater number of false positives than true variants, thereby reducing the potential for replication by a risk score. Large-scale $\mathrm{BMI} /$ obesity-associated $\mathrm{CNV}$ meta-analyses are needed to validate reported variants and to accurately characterize the magnitude of their effects.

We also assessed whether the integrated models were clinically useful for obesity risk prediction. A model including standard covariates, SNP-GRSS and three obesity-associated CNVs demonstrated significant discriminative ability to predict overweight and obesity

Table 4 Discriminative accuracy of covariates, SNP-GRSS and CNV predicting BMI category in European- and African-Americans

\begin{tabular}{|c|c|c|c|c|c|c|}
\hline Model & AUC & $95 \% \mathrm{Cl}$ & Asy. Sig. of Model & $\Delta \mathrm{AUC}$ & $\% \Delta$ AUC & $p \Delta A \cup C$ \\
\hline \multicolumn{7}{|c|}{ Overweight: $n=1443$ (61.4\%) } \\
\hline 1. Covariates & 0.679 & {$[0.657,0.700]$} & $2.68 \times 10^{-48}$ & - & - & - \\
\hline 2. Model $1+$ SNP-GRSS & 0.692 & {$[0.671,0.714]$} & $9.23 \times 10^{-56}$ & 0.013 & $1.91 \%$ & 0.001 \\
\hline 3. Model $2+$ CNV & 0.694 & {$[0.672,0.715]$} & $1.27 \times 10^{-56}$ & 0.002 & $0.28 \%$ & 0.372 \\
\hline \multicolumn{7}{|c|}{ Obese Class I: $n=632$ (26.9\%) } \\
\hline 1. Covariates & 0.621 & {$[0.594,0.647]$} & $2.74 \times 10^{-19}$ & - & - & - \\
\hline 2. Model $1+$ SNP-GRSS & 0.661 & {$[0.637,0.686]$} & $2.77 \times 10^{-33}$ & 0.040 & $6.44 \%$ & 0.0001 \\
\hline 3. Model $2+C N V$ & 0.662 & {$[0.638,0.687]$} & $1.12 \times 10^{-33}$ & 0.001 & $0.15 \%$ & 0.662 \\
\hline \multicolumn{7}{|c|}{ Obese Class II: $n=264$ (11.2\%) } \\
\hline 1. Covariates & 0.648 & {$[0.610,0.685]$} & $5.22 \times 10^{-15}$ & - & - & - \\
\hline 2. Model $1+$ SNP-GRSS & 0.681 & {$[0.646,0.716]$} & $6.97 \times 10^{-22}$ & 0.033 & $5.09 \%$ & 0.025 \\
\hline 3. Model $2+C N V$ & 0.690 & {$[0.656,0.725]$} & $5.58 \times 10^{-24}$ & 0.009 & $1.32 \%$ & 0.123 \\
\hline \multicolumn{7}{|c|}{ Obese Class III: $n=106,(4.5 \%)$} \\
\hline 1. Covariates & 0.711 & {$[0.660,0.762]$} & $1.97 \times 10^{13}$ & - & - & - \\
\hline 2. Model $1+$ SNP-GRSS & 0.741 & {$[0.692,0.790]$} & $4.81 \times 10^{-17}$ & 0.030 & $4.22 \%$ & 0.029 \\
\hline 3. Model $2+C N V$ & 0.750 & {$[0.702,0.797]$} & $3.15 \times 10^{-18}$ & 0.009 & $1.21 \%$ & 0.152 \\
\hline
\end{tabular}

Note: $\mathrm{BMI}=$ body mass index $\mathrm{kg} / \mathrm{m}^{2}$, SNP = single nucleotide polymorphism, SNP-GRSS = genetic risk sum score constructed from imputed probability of carrying 32 BMI-associated SNPs weighted by effect size reported in Speliotes et al. 2010, CNV = copy number variation, AUC = area-under the receiver operator criteria curve, Asy. Sig. = asymptotic significance, $\triangle A U C=$ change in AUC from previous model, $\% \triangle A U C=$ percent change in AUC from previous model, $p \Delta$ AUC $=$ statistical significance of change in AUC, Overweight $=B M I \geq 25 \mathrm{~kg} / \mathrm{m}^{2}$, Obese I $=B M I \geq 30 \mathrm{~kg} / \mathrm{m}^{2}$, Obese $I I=B M I \geq 35 \mathrm{~kg} / \mathrm{m}^{2}, O b e s e I I=B M l \geq 40 \mathrm{~kg} / \mathrm{m}^{2}$ Covariates $=P C 1, P C 4, P C 8$, sex, age, $A D, N D, P C 1 *$ sex, age ${ }^{*} A D, P C=$ principal component score, Age = age at interview, $A D=$ alcohol dependence, $N D=$ nicotine dependence. 
classification, with maximum discriminative ability when predicting class III obesity (AUC $=0.750$ ). Other studies using SNP-GRSS to predict obesity have incorporated 8-32 SNPs and reported AUC estimates ranging from 0.574 to 0.597 [9,50,52-54]. Although our AUC estimates were statistically significant, they fell short of the threshold used in clinical practice for screening (0.8) and an important extension of this work is model validation in independent samples.

There are several possible extensions of the work presented here. First, SAGE participants consisted of a selected sample for substance-use behaviors. Although we have included AD and ND as covariates in all analyses, research has shown these phenotypes to have complex relationships with body composition [55,56], and this may complicate interpretation. Future research should test for associations in both larger and population-based samples. An additional extension of this work is to incorporate variation detected from other obesity phenotypes such as waist-to-hip ratio $[57,58]$, extremes of the BMI trait distribution [59], and from diverse populations [14]. Additionally, fine mapping efforts are needed and will likely identify lower-frequency variants, which are typically not genotyped on commercial GWAS-arrays. Therefore a further extension of the work presented here is to include lower-frequency SNPs and INDELs identified by large-scale exome and genome sequencing efforts. Another important extension of an integrated model of BMI and obesity is to incorporate the moderating effects of the environment. At least two of the BMIvalidated SNPs exhibit gene by environment interactions (GxE) $[60,61]$. For example, a large meta-analysis found that in physically active adults the effect of the FTO risk allele on obesity was attenuated by $27 \%$ [62]. Given the considerable impact of the environment on body composition, future research needs to incorporate environmental variables into models of disease and risk prediction. Despite the potential limitations of the current study, this work provides a framework for integrating common and rare variation as both an alternative form of replication of genetic effects as well as for risk prediction of complex traits.

\section{Additional files}

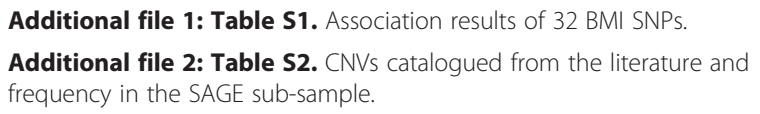

Additional file 3: Table S3. Comparison of the association of GRSSs with BMl constructed by count and weighted methods by self-reported ancestry.

Additional file 4: Table S4. Common and rare CNV-GRSS.

Additional file 5: Table S5. Linear models predicting BMI by ancestry.

Additional file 6: Table S6. Discriminative accuracy of covariates, SNPGRSS and CNV predicting BMI category by self-reported ancestry.
Competing interests

The authors declare that they have no competing interests.

\section{Authors' contributions}

REP was involved in the conception and design of the study, performed statistical analyses, interpreted the data, and drafted the manuscript. BTW and $\mathrm{HHH}$ were involved in the conception and design of the study, interpretation of data, and were involved in the revision process. PL called CNVs and provided the corresponding methodological text. JRK, VMH, LOB, $J I N, H J E$, and DMD contributed to the acquisition and interpretation of data and were involved in the revision process. All authors read and approved the final manuscript.

\section{Acknowledgments}

This work was supported by the National Institute on Drug Abuse [DA26119]. Funding support for the Study of Addiction: Genetics and Environment (SAGE) was provided through the NIH Genes, Environment and Health Initiative [GEI] [U01 HG004422]. SAGE is one of the genome-wide association studies funded as part of the Gene Environment Association Studies (GENEVA) under GEl. Assistance with phenotype harmonization and genotype cleaning, as well as with general study coordination, was provided by the GENEVA Coordinating Center [U01 HG004446]. Assistance with data cleaning was provided by the National Center for Biotechnology Information. Support for collection of datasets and samples was provided by the Collaborative Study on the Genetics of Alcoholism (COGA) [U10 AA008401], the Collaborative Genetic Study of Nicotine Dependence (COGEND) [P01 CA089392], and the Family Study of Cocaine Dependence (FSCD) [R01 DA013423, R01 DA019963]. Funding support for genotyping, which was performed at the Johns Hopkins University Center for Inherited Disease Research, was provided by the NIH GEI [U01 HG004438], the National Institute on Alcohol Abuse and Alcoholism, the National Institute on Drug Abuse, and the NIH contract "High throughput genotyping for studying the genetic contributions to human disease" [HHSN862200782096C]. We wish to thank the individuals who volunteered for the SAGE sample for their participation and the SARA Computing and Networking Services (https://surfsara.nl/ systems/lisa) for their support in using the Lisa Compute Cluster to generate principal component scores. Special thanks to Dr. T. Bernard Bigdeli, Ph.D., for guidance on imputation procedures and Dr. Charles O. Gardner, Ph.D., for statistical consultation.

\section{Author details}

${ }^{1}$ Virginia Institute for Psychiatric and Behavioral Genetics, Department of Human and Molecular Genetics, School of Medicine, Virginia Commonwealth University, Biotech I, 800 E. Leigh Street, Richmond, VA 23298-0126, USA. ${ }^{2}$ Virginia Institute for Psychiatric and Behavioral Genetics, Department of Human and Molecular Genetics, Massey Cancer Center, School of Medicine, Virginia Commonwealth University, Richmond, VA 23298, USA. ${ }^{3}$ Department of Psychiatry, Washington University, St. Louis, MO 63105, USA. ${ }^{4}$ Department of Psychiatry, University of lowa, lowa City, IA 52240, USA. ${ }^{5}$ Department of Psychiatry, School of Medicine, University of Connecticut, Farmington, CT 06030, USA. ${ }^{6}$ Institute of Psychiatric Research, Department of Psychiatry, School of Medicine, Indiana University, Indianapolis, IN 46226, USA.

7 Department of Biochemistry and Molecular Biology, School of Medicine, Indiana University, Indianapolis, IN 46226, USA. ${ }^{8}$ Virginia Institute for Psychiatric and Behavioral Genetics, Virginia Commonwealth University, Richmond, VA 23298, USA. 'Virginia Institute for Psychiatric and Behavioral Genetics, Department of Psychiatry, School of Medicine, Virginia

Commonwealth University, Richmond, VA 23298, USA.

Received: 12 June 2013 Accepted: 27 April 2014

Published: 14 May 2014

\section{References}

1. Centers for Disease Control and Prevention. [http://www.cdc.gov]

2. Ogden CL, Yanovski SZ, Carroll MD, Flegal KM: The epidemiology of obesity. Gastroenterology 2007, 132(6):2087-2102.

3. Apovian C, Gokce N: Obesity and cardiovascular disease. Circulation 2012, 125(9):1178-1182.

4. Chen L, Magliano D, Zimmet P: The worldwide epidemiology of type 2 diabetes mellitus-present and future perspectives. Nat Rev Endocrinol 2011, 8(4):228. 
5. Faulds M, Dahlman Wright K: Metabolic diseases and cancer risk. Curr Opin Oncol 2012, 24(1):58-61.

6. Maes HH, Neale MC, Eaves LJ: Genetic and environmental factors in relative body weight and human adiposity. Behav Genet 1997, 27(4):325-351.

7. Loos RJF: Recent progress in the genetics of common obesity. Br J Clin Pharmacol 2009, 68(6):811.

8. Day F, Loos RJF: Developments in obesity genetics in the era of genome-wide association studies. J Nutrigenet Nutrigenomics 2011, 4(4):222-238.

9. Speliotes EK, Willer CJ, Berndt SI, Monda KL, Thorleifsson G, Jackson AU, Lango Allen H, Lindgren CM, Luan J, Magi R, Randall JC, Vedantam S, Winkler TW, Qi L, Workalemahu T, Heid IM, Steinthorsdottir V, Stringham HM, Weedon MN, Wheeler E, Wood AR, Ferreira T, Weyant RJ, Segre AV, Estrada K, Liang L, Nemesh J, Park JH, Gustafsson S, Kilpelainen TO, et al: Association analyses of 249,796 individuals reveal 18 new loci associated with body mass index. Nat Genet 2010, 42(11):937

10. Kang SJ, Chiang CW, Palmer CD, Tayo BO, Lettre G, Butler JL, Hackett R, Adeyemo AA, Guiducci C, Berzins I, Nguyen TT, Feng T, Luke A, Shriner D, Ardlie K, Rotimi C, Wilks R, Forrester T, McKenzie CA, Lyon HN, Cooper RS, Zhu X, Hirschhorn JN: Genome-wide association of anthropometric traits in African- and African-derived populations; Human molecular genetics. Hum Mol Genet 2010, 19:2725-38.

11. Ng MC, Hester JM, Wing MR, Li J, Xu J, Hicks PJ, Roh BH, Lu L, Divers J, Langefeld CD, Freedman BI, Palmer ND, Bowden DW: Genome-wide association of BMI in African Americans. Obesity (Silver Spring) 2012, 20(3):622-627.

12. Hester JM, Wing MR, Li J, Palmer ND, Xu J, Hicks PJ, Roh BH, Norris JM, Wagenknecht LE, Langefeld CD, Freedman Bl, Bowden DW, Ng MCY Implication of European-derived adiposity loci in African Americans. Int J Obes 2012, 36(3):465-473.

13. Peters U, North KE, Sethupathy P, Buyske S, Haessler J, Jiao S, Fesinmeyer MD, Jackson RD, Kuller LH, Rajkovic A, Lim U, Cheng I, Schumacher F, Wilkens L, Li R, Monda K, Ehret G, Nguyen KD, Cooper R, Lewis CE, Leppert M, Irvin MR, Gu CC, Houston D, Buzkova P, Ritchie M, Matise TC, Le Marchand L, Hindorff LA, Crawford DC, et al: A systematic mapping approach of $16 \mathrm{q} 12.2 / \mathrm{FTO}$ and BMI in more than 20,000 African Americans narrows in on the underlying functional variation: results from the Population Architecture using Genomics and Epidemiology (PAGE) study. PLoS Genet 2013, 9(1):e1003171.

14. Monda KL, Chen GK, Taylor KC, Palmer C, Edwards TL, Lange LA, Ng MCY, Adeyemo AA, Allison MA, Bielak LF, Chen G, Graff M, Irvin MR, Rhie SK, Li G, Liu Y, Liu Y, Lu Y, Nalls MA, Sun YV, Wojczynski MK, Yanek LR, Aldrich MC, Ademola A, Amos Cl, Bandera EV, Bock CH, Britton A, Broeckel U, Cai Q, et al: A meta-analysis identifies new loci associated with body mass index in individuals of African ancestry. Nat Genet 2013, 45(6):690-696.

15. Yang J, Manolio T, Pasquale L, Boerwinkle E, Caporaso N, Cunningham J, De Andrade M, Feenstra B, Feingold E, Hayes MG, Hill W, Landi M, Alonso A, Lettre G, Lin P, Ling H, Lowe W, Mathias R, Melbye M, Pugh E, Cornelis M, Weir B, Goddard M, Visscher P: Genome partitioning of genetic variation for complex traits using common SNPs. Nat Genet 2011, 43(6):519-525.

16. Ahituv N, Kavaslar N, Schackwitz W, Ustaszewska A, Martin J, Hebert S, Doelle H, Ersoy B, Kryukov G, Schmidt S, Yosef N, Ruppin E, Sharan R, Vaisse C, Sunyaev S, Dent R, Cohen J, McPherson R, Pennacchio L: Medical sequencing at the extremes of human body mass. Am J Hum Genet 2007, 80(4):779-791

17. Walters RG, Jacquemont $S$, Valsesia A, De Smith AJ, Martinet D, Andersson J, Falchi M, Chen F, Andrieux J, Lobbens S, Delobel B, Stutzmann F, El-Sayed Moustafa JS, Chèvre J, Lecoeur C, Vatin V, Bouquillon S, Buxton JL, Boute O, Holder-Espinasse M, Cuisset J, Lemaitre M, Ambresin A, Brioschi A, Gaillard M, Giusti V, Fellmann F, Ferrarini A, Hadjikhani N, Campion D, et al: A new highly penetrant form of obesity due to deletions on chromosome 16p11.2. Nature 2010, 463(7281):671.

18. Bochukova E, Huang N, Keogh J, Henning E, Purmann C, Blaszczyk K, Saeed S, Hamilton-Shield J, Clayton-Smith J, O'Rahilly S, Hurles M, Faroogi IS: Large, rare chromosomal deletions associated with severe early-onset obesity. Nature 2010, 463(7281):666

19. Wang K, Li W, Glessner J, Grant SFA, Hakonarson H, Price RA: Large copynumber variations are enriched in cases with moderate to extreme obesity. Diabetes 2010, 59(10):2690-2694.

20. Bachmann Gagescu R, Mefford H, Cowan C, Glew G, Hing A, Wallace S, Bader P, Hamati A, Reitnauer P, Smith R, Stockton D, Muhle H, Helbig I,
Eichler E, Ballif B, Rosenfeld J, Tsuchiya K: Recurrent 200-kb deletions of 16p11.2 that include the $\mathrm{SH} 2 \mathrm{~B} 1$ gene are associated with developmental delay and obesity. Gen Med 2010, 12(10):641.

21. Glessner J, Bradfield J, Wang K, Takahashi N, Zhang H, Sleiman P, Mentch F, Kim C, Hou C, Thomas K, Garris M, Deliard S, Frackelton E, Otieno FG, Zhao J, Chiavacci R, Li M, Buxbaum J, Berkowitz R, Hakonarson H, Grant SFA: A genomewide study reveals copy number variants exclusive to childhood obesity cases. Am J Hum Genet 2010, 87(5):661.

22. Shinawi M, Sahoo T, Maranda B, Skinner SA, Skinner C, Chinault C, Zascavage R, Peters $S$, Patel A, Stevenson R, Beaudet A: 11p14.1 microdeletions associated with ADHD, autism, developmental delay, and obesity. Am J Med Genet $A$ 2011, 155A(6):1272-1280.

23. Jacquemont S, Reymond A, Zufferey F, Harewood L, Walters RG, Kutalik Z, Martinet D, Shen Y, Valsesia A, Beckmann ND, Thorleifsson G, Belfiore M, Bouquillon S, Campion D, De Leeuw N, De Vries BBA, Esko T, Fernandez BA, Fernandez-Aranda F, Fernandez-Real JM, Gratacos M, Guilmatre A, Hoyer J, Jarvelin MR, Kooy FR, Kurg A, Le Caignec C, Mannik K, Platt OS, Sanlaville D, et al: Mirror extreme BMI phenotypes associated with gene dosage at the chromosome 16p11.2 locus. Nature 2011, 478:97-102

24. Sofos E, Pescosolido MF, Quintos JB, Abuelo D, Gunn S, Hovanes K, Morrow EM, Shur N: A novel familial 11p15.4 microduplication associated with intellectual disability, dysmorphic features, and obesity with involvement of the ZNF214 gene. Am J Med Genet A 2012, 158A(1):50-58.

25. Bierut L, Agrawal A, Bucholz K, Doheny K, Laurie C, Pugh E, Fisher S, Fox L, Howells W, Bertelsen S, Hinrichs A, Almasy L, Breslau N, Culverhouse R, Dick D, Edenberg H, Foroud T, Grucza R, Hatsukami D, Hesselbrock V, Johnson E, Kramer J, Krueger R, Kuperman S, Lynskey M, Mann K, Neuman R, Nthen $M$, Nurnberger J, Porjesz B, et al: A genome-wide association study of alcohol dependence. Proc Natl Acad Sci U S A 2010, 107(11):5082-5087.

26. Bucholz KK, Cadoret R, Cloninger CR, Dinwiddie SH, Hesselbrock VM, Nurnberger Jl, Reich T, Schmidt I, Schuckit MA: A new, semi-structured psychiatric interview for use in genetic linkage studies: a report on the reliability of the SSAGA. J Stud Alcohol 1994, 55(2):149-158.

27. American Psychiatric Association., American Psychiatric Association. Task Force on DSM-IV: Diagnostic and Statistical Manual of Mental Disorders: DSM-IV-TR. Washington, DC: American Psychiatric Association; 2000.

28. Howie B, Donnelly P, Marchini J: A flexible and accurate genotype imputation method for the next generation of genome-wide association studies. PLoS Genet 2009, 5(6):e1000529-e1000529.

29. Howie B, Marchini J, Stephens M: Genotype imputation with thousands of genomes. G3 2011, 1(6):457-470.

30. 1000 Genomes Project Consortium: A map of human genome variation from population-scale sequencing. Nature 2010, 467(7319):1061-1073.

31. Price A, Patterson N, Plenge R, Weinblatt M, Shadick N, Reich D: Principal components analysis corrects for stratification in genome-wide association studies. Nat Genet 2006, 38(8):904.

32. Patterson N, Price A, Reich D: Population structure and eigenanalysis. PLoS Genet 2006, 2(12):e190.

33. Shriner D: Investigating population stratification and admixture using eigenanalysis of dense genotypes. Heredity 2011, 107(5):413-420.

34. Gauderman WJ MJ: QUANTO 1.1: A Computer Program for Power and Sample Size Calculations for Genetic-Epidemiology Studies. 2006.

35. Wang K, Li M, Hadley D, Liu R, Glessner J, Grant SFA, Hakonarson H, Bucan M: PennCNV: an integrated hidden Markov model designed for highresolution copy number variation detection in whole-genome SNP genotyping data. Genome Res 2007, 17(11):1665-1674.

36. Colella S, Yau C, Taylor J, Mirza G, Butler H, Clouston P, Bassett A, Seller A, Holmes C, Ragoussis J: QuantiSNP: an Objective Bayes Hidden-Markov Model to detect and accurately map copy number variation using SNP genotyping data. Nucleic Acids Res 2007, 35(6):2013-2025.

37. Diskin S, Li M, Hou C, Yang S, Glessner J, Hakonarson H, Bucan M, Maris J, Wang $\mathrm{K}$ : Adjustment of genomic waves in signal intensities from wholegenome SNP genotyping platforms. Nucleic Acids Res 2008, 36(19):e126-e126.

38. Lin $\mathrm{P}$, Hartz $\mathrm{S}$, Wang J, Krueger R, Foroud T, Edenberg H, Nurnberger J, Brooks A, Tischfield J, Almasy L, Webb B, Hesselbrock V, Porjesz B, Goate A, Bierut $L$, Rice J: Copy number variation accuracy in genome-wide association studies. Hum Hered 2011, 71(3):141-147.

39. Sanders S, Ercan Sencicek AG, Hus V, Luo R, Murtha M, Moreno-De-Luca D, Chu S, Moreau M, Gupta A, Thomson S, Mason C, Bilguvar K, Celestino-Soper PBS, Choi M, Crawford E, Davis L, Wright NRD, Dhodapkar R, DiCola M, DiLullo N, Fernandez T, Fielding Singh V, Fishman D, Frahm S, Garagaloyan R, Goh G, 
Kammela S, Klei L, Lowe J, Lund S, et al: Multiple recurrent de novo CNVs, including duplications of the 7q11.23 Williams syndrome region, are strongly associated with autism. Neuron 2011, 70(5):863-885.

40. Need A, Ge D, Weale M, Maia J, Feng S, Heinzen E, Shianna K, Yoon W, Kasperaviciūte D, Gennarelli M, Strittmatter W, Bonvicini C, Rossi G, Jayathilake K, Cola P, McEvoy J, Keefe RSE, Fisher EMC, St Jean P, Giegling I, Hartmann A, Mller H, Ruppert A, Fraser G, Crombie C, Middleton L, St Clair D, Roses A, Muglia P, Francks C, et al: A genome-wide investigation of SNPs and CNVs in schizophrenia. PLoS Genet 2009, 5(2):e1000373-e1000373.

41. Johnson A, Handsaker R, Pulit S, Nizzari M, O'Donnell C, De Bakker PIW: SNAP: a web-based tool for identification and annotation of proxy SNPs using HapMap. Bioinformatics 2008, 24(24):2938.

42. Purcell S, Neale B, Todd-Brown K, Thomas L, Ferreira MAR, Bender D, Maller J, Sklar P, De Bakker PIW, Daly M, Sham P: PLINK: a tool set for whole-genome association and population-based linkage analyses. Am J Hum Genet 2007, 81(3):559.

43. R Development Core Team: R: A Language and Environment for Statistical Computing. 叉: 邓; 2011.

44. Peterson R, Maes H, Holmans P, Sanders A, Levinson D, Shi J, Kendler K, Gejman P, Webb B: Genetic risk sum score comprised of common polygenic variation is associated with body mass index. Hum Genet 2011, 129(2):221-230.

45. Li B, Leal S: Methods for detecting associations with rare variants for common diseases: application to analysis of sequence data. Am J Hum Genet 2008, 83(3):311-321.

46. Bansal V, Libiger O, Torkamani A, Schork N: Statistical analysis strategies for association studies involving rare variants. Nature reviews. Genetic 2010, 11(11):773-785.

47. Vergara I, Norambuena T, Ferrada E, Slater A, Melo F: StAR: a simple tool for the statistical comparison of ROC curves. BMC Bioinforma 2008 9:265-265.

48. Willer CJ, Speliotes EK, Loos RJ, Li S, Lindgren CM, Heid IM, Berndt SI, Elliott AL, Jackson AU, Lamina C, Lettre G, Lim N, Lyon HN, McCarroll SA, Papadakis K, Qi L, Randall JC, Roccasecca RM, Sanna S, Scheet P, Weedon MN Wheeler E, Zhao JH, Jacobs LC, Prokopenko I, Soranzo N, Tanaka T, Timpson NJ, Almgren $P$, Bennett $A$, et al: Six new loci associated with body mass index highlight a neuronal influence on body weight regulation. Nat Genet 2009, 41(1):25-34.

49. Jarick I, Vogel CIG, Scherag S, Schfer H, Hebebrand J, Hinney A, Scherag A: Novel common copy number variation for early onset extreme obesity on chromosome 11q11 identified by a genome-wide analysis. Hum Mol Genet 2011, 20(4):840.

50. Belsky DW, Moffitt TE, Baker TB, Biddle AK, Evans JP, Harrington H, Houts R, Meier M, Sugden K, Williams B, Poulton R, Caspi A: Polygenic risk and the developmental progression to heavy, persistent smoking and nicotine dependence: Evidence from a 4-decade longitudinal study. JAMA Psychiatry 2013, 1-9.

51. Walters RG, Coin LM, Ruokonen A, De Smith AJ, El-Sayed Moustafa JS, Jacquemont S, Elliott P, Esko T, Hartikainen A, Laitinen J, Männik K, Martinet D, Meyre D, Nauck M, Schurmann C, Sladek R, Thorleifsson G, Thorsteinsdóttir U, Valsesia A, Waeber G, Zufferey F, Balkau B, Pattou F, Metspalu A, Völzke H, Vollenweider P, Stefansson K, Järvelin M, Beckmann JS, Froguel P, et al: Rare genomic structural variants in complex disease: lessons from the Replication of Associations with Obesity. PLoS One 2013, 8(3):e58048.

52. Renström F, Payne F, Nordström A, Brito E, Rolandsson O, Hallmans G, Barroso I, Nordstrm P, Franks P: Replication and extension of genomewide association study results for obesity in 4923 adults from northern Sweden. Hum Mol Genet 2009, 18(8):1489.

53. Li S, Zhao J, Luan J, Luben R, Rodwell S, Khaw K, Ong K, Wareham N, Loos RJF: Cumulative effects and predictive value of common obesitysusceptibility variants identified by genome-wide association studies. Am J Clin Nutr 2010, 91(1):184

54. Cheung CY, Tso AW, Cheung BM, Xu A, Ong KL, Fong CH, Wat NM, Janus ED, Sham PC, Lam KS: Obesity Susceptibility Genetic Variants Identified from Recent Genome-Wide Association Studies: implications in a Chinese population. J Clin Endocrinol Metab 2010, 95(3):1395-1403.

55. Chiolero A, Faeh D, Paccaud F, Cornuz J: Consequences of smoking for body weight, body fat distribution, and insulin resistance. Am J Clin Nutr 2008, 87(4):801.

56. Lourenço S, Oliveira A, Lopes C: The effect of current and lifetime alcohol consumption on overall and central obesity. Eur J Clin Nutr 2012, 66(7):813.
57. Heid IM, Jackson AU, Randall JC, Winkler TW, Qi L, Steinthorsdottir V, Thorleifsson G, Zillikens MC, Speliotes EK, Magi R, Workalemahu T, White CC, Bouatia-Naji N, Harris TB, Berndt SI, Ingelsson E, Willer CJ, Weedon MN, Luan J, Vedantam S, Esko T, Kilpelainen TO, Kutalik Z, Li S, Monda KL, Dixon AL, Holmes CC, Kaplan LM, Liang L, Min JL, et al: Meta-analysis identifies 13 new loci associated with waist-hip ratio and reveals sexual dimorphism in the genetic basis of fat distribution. Nat Genet 2010, 42(11):949-960.

58. Lindgren CM, Heid IM, Randall JC, Lamina C, Steinthorsdottir V, Qi L, Speliotes EK, Thorleifsson G, Willer CJ, Herrera BM, Jackson AU, Lim N, Scheet P, Soranzo N, Amin N, Aulchenko YS, Chambers JC, Drong A, Luan J, Lyon HN, Rivadeneira F, Sanna S, Timpson NJ, Zillikens MC, Zhao JH, Almgren P, Bandinelli S, Bennett AJ, Bergman RN, Bonnycastle LL, et al: Genome-wide association scan meta-analysis identifies three Loci influencing adiposity and fat distribution. PLoS Genet 2009, 5(6):e1000508.

59. Berndt SI, Gustafsson S, Magi R, Ganna A, Wheeler E, Feitosa MF, Justice AE, Monda KL, Croteau-Chonka D, Day FR, Esko T, Fall T, Ferreira T, Gentilini D, Jackson AU, Luan J, Randall JC, Vedantam S, Willer CJ, Winkler TW, Wood AR, Workalemahu T, Hu Y, Lee SH, Liang L, Lin D, Min JL, Neale BM, Thorleifsson G, Yang J, et al: Genome-wide meta-analysis identifies 11 new loci for anthropometric traits and provides insights into genetic architecture. Nat Genet 2013, 45(5):501-512.

60. Rampersaud E, Mitchell B, Pollin T, Fu M, Shen H, O'Connell J, Ducharme J, Hines S, Sack P, Naglieri R, Shuldiner A, Snitker S: Physical activity and the association of common FTO gene variants with body mass index and obesity. Arch Intern Med 2008, 168(16):1791.

61. Qi L, Kraft P, Hunter D, Hu F: The common obesity variant near MC4R gene is associated with higher intakes of total energy and dietary fat, weight change and diabetes risk in women. Hum Mol Genet 2008, 17(22):3502.

62. Kilpeläinen TO, Qi L, Brage S, Sharp SJ, Sonestedt E, Demerath E, Ahmad T, Mora S, Kaakinen M, Sandholt CH, Holzapfel C, Autenrieth CS, Hyppönen E Cauchi S, He M, Kutalik Z, Kumari M, Stančáková A, Meidtner K, Balkau B, Tan JT, Mangino M, Timpson NJ, Song Y, Zillikens MC, Jablonski KA, Garcia ME, Johansson S, Bragg-Gresham JL, Wu Y, et al: Physical activity attenuates the influence of FTO variants on obesity risk: a meta-analysis of 218,166 adults and 19,268 children. PLoS Med 2011, 8(11):e1001116.

doi:10.1186/1471-2164-15-368

Cite this article as: Peterson et al:: On the association of common and rare genetic variation influencing body mass index: a combined SNP and CNV analysis. BMC Genomics 2014 15:368.

\section{Submit your next manuscript to BioMed Central and take full advantage of:}

- Convenient online submission

- Thorough peer review

- No space constraints or color figure charges

- Immediate publication on acceptance

- Inclusion in PubMed, CAS, Scopus and Google Scholar

- Research which is freely available for redistribution 